Article

\title{
Study on Mechanical and Viscoelastic Properties of Asphalt Mixture Modified by Diatomite and Crumb Rubber Particles
}

\author{
Chunyu Liang, Hao Zhang, Zhengwei Gu *, Xin Xu and Jinxin Hao \\ College of Transportation, Jilin University, Changchun 130025, China; liangcy@jlu.edu.cn (C.L.); \\ hz20@mails.jlu.edu.cn (H.Z.); xinxu19@mails.jlu.edu.cn (X.X.); haojx20@mails.jlu.edu.cn (J.H.) \\ * Correspondence: gzw@jlu.edu.cn; Tel.: +86-151-4303-7549
}

Received: 16 November 2020; Accepted: 30 November 2020; Published: 7 December 2020

\begin{abstract}
To optimize the properties of asphalt mixtures and make full use of waste rubber tires, diatomite and crumb rubber particles were applied to reinforce the asphalt mixtures in this study. The rutting tests, the three-point bending tests, the freeze-thaw splitting tests, and the uniaxial compression creep tests were performed to analyze the effects of asphalt types and aggregate gradation on the pavement properties of diatomite and crumb rubber particles reinforced asphalt mixtures (DRPAM). Subsequently, the creep and relaxation characteristics of DRPAM were analyzed by the Burgers model, the modified Burgers model, the second-order extensive Maxwell model, and the Scott-Blair model. The results show that rubber particles and diatomite can reinforce the high temperature, low temperature, and viscoelastic properties of asphalt mixtures, although the improvement effect is weaker than styrene-butadiene-styrene (SBS). Consequently, it is concluded that rubber particle and diatomite compound modified asphalt mixture with suspension dense gradation and SBS binder will have better performance.
\end{abstract}

Keywords: asphalt mixture; mechanical properties; viscoelastic properties; diatomite; crumb rubber particles; creep tests

\section{Introduction}

With the rapid growth of the car ownership in recent decades, a large number of waste rubber tires are produced every year, which seriously polluted the environment and occupied arable land. Therefore, it has been an urgent problem to recycle and reuse these waste tires, in which crushing waste tires into rubber powder or rubber particles and applying them to the highway construction industry has become one of the main development directions of waste tire treatment [1,2].

Venudharan et al. [3] evaluated the effect of crumb particles on rutting resistance and viscosity-temperature susceptibility base on temperature-frequency oscillation and multiple stress creep and recovery tests. The results showed that the finer the crumb rubber particles in the gradation, the better the rutting resistance and the lower the viscosity-temperature sensitivity. Wang et al. [4] and Daly et al. [5] pointed out that crumb rubber particle size had an important impact on the low-temperature performance of asphalt mixtures. Wang et al. [6] and Abdul Hassan et al. [7] reported that crumb rubber could reduce the low-temperature creep stiffness and resilient modulus of crumb rubber modified asphalt. In addition, with the decrease of the particle size of rubber particles, crumb rubber modified asphalt had been proved to have better low-temperature properties, elasticity and adhesion [8,9]. Behnood et al. studied the influence of styrene-butadiene-styrene (SBS) and rubber powder on the high and low temperature performance of asphalt by the dynamic shear rheometer (DSR) and the bending beam rheometer (BBR) $[10,11]$. The results showed that SBS and rubber powder could 
improve the high temperature performance of asphalt mixture, and rubber powder can significantly reduce the stiffness of asphalt [10]. Qian et al. [12] claimed the combination of crumb rubber particles and SBS copolymers had a synergistic effect on asphalt's rheological properties. Wei et al. [13] pointed out that mechanical properties and anti-icing performance of the control asphalt mixture could be improved by crumb rubber and diatomite.

It can be found that rubber particles alone in asphalt mixture may have adverse effects on the performance of asphalt mixture. By comparison, diatomite, as a good inorganic modifier, is often employed to enhance the road performance of mixtures [14]. Zhang et al. [15] claimed that adding diatomite in asphalt could reduce the equivalent brittle point of asphalt and reinforce the low-temperature properties of asphalt. Yang et al. [16] pointed out that the moisture susceptibility and the high-temperature stability of asphalt mixtures could be improved by adding the diatomite into asphalt mixtures, but their crack and fatigue resistance could not be improved. Tan et al. [17] reported that the resistance cracking at low temperature of diatomite reinforced asphalt mixtures was better than that of base asphalt mixtures. Some studies have also pointed out that the combined use of diatomite and other modifiers can further reinforce the road properties of asphalt mixtures [18-20]. Some recycled materials such as plastic waste and jet grouting waste could also be used to enhance the performance of asphalt or asphalt mastics [21,22].

It can be seen from the above literatures that the current researches on rubber particle modified asphalt mixture are mainly focused on conventional road performance and deicing characteristics. Moreover, it is rare to analyze the effect of diatomite and rubber particle on the viscoelastic properties of asphalt mixtures, and the effect of gradation and asphalt types on the pavement performance and viscoelastic properties of rubber particles and diatomite compound modified asphalt mixtures have not been reported in the previous literature. For this reason, eight groups of asphalt mixture samples were fabricated by using matrix asphalt and SBS modified asphalt firstly, and then their mechanical properties and viscoelastic properties were compared by rutting tests, low-temperature trabecular bending tests, freeze-thaw splitting tests, and uniaxial compression creep tests. Finally, the effects of asphalt types and gradation on the mechanical properties and viscoelastic properties of composite modified asphalt mixture were analyzed. It is expected to provide a theoretical reference for the application of rubber particle and diatomite composite reinforced asphalt mixtures in practical engineering.

\section{Materials and Methods}

\subsection{Materials}

The base asphalt and SBS modified asphalt were used in this study, and their physical properties are presented in Table 1. The content of SBS in asphalt is $4 \%$. The crumb rubber particles come from Binzhou City Shangdong Province, with the particle size of 1-3 mm, and the content of the crumb rubber particles in asphalt mixtures is $3 \%$ (mass ratio of mineral aggregate) [13]. Considering the convenience of practical application in engineering, the mixing method of rubber particles adopts the external mixing method. That is, the original mineral material gradation of the asphalt mixture is not changed, and rubber particles are mixed in the mixing process. The physical properties of rubber particles are shown in Table 2. The diatomite with a size below $0.075 \mathrm{~mm}$ was utilized to enhance the asphalt mixtures, whose composition is presented in Table 3. According to the standard (JTG E20-2011 T0736-2011), eight types of asphalt mixtures included suspended dense gradation and framework dense gradation were prepared in this study [23]. The grading curve is shown in Figure 1. In subsequent tests, the rutting plate specimens were fabricated by wheel rolling method, and the cylindrical specimens (100 $\mathrm{mm}$ in diameter and $63.5 \mathrm{~mm}$ in height) for freeze-thaw splitting tests and creep tests were fabricated by the Superpave Gyratory Compactor (SGC). The specific grouping number and the optimum asphalt-aggregate ratio are shown in Table 4. The optimum asphalt-aggregate ratio was determined according to the standard (JTG F40-2004) [24]. According to the standard, the design volume of air voids of suspended dense graded asphalt mixture and skeleton dense graded asphalt 
mixture are $4 \%$ and $3.5 \%$, respectively. The basalt aggregate was used, and all performance indexes meet the specification requirements, as shown in Table 5 .

Table 1. Physical properties of asphalt.

\begin{tabular}{|c|c|c|c|c|}
\hline \multirow{2}{*}{ Properties } & \multicolumn{2}{|c|}{ Base Asphalt } & \multicolumn{2}{|c|}{ SBS Modified Asphalt } \\
\hline & Standard & Value & Standard & Value \\
\hline Density $\left(15^{\circ} \mathrm{C}, \mathrm{g} / \mathrm{cm}^{3}\right)$ & - & 1.017 & - & 1.014 \\
\hline Penetration $\left(25^{\circ} \mathrm{C}, 0.1 \mathrm{~mm}\right)$ & $80-100$ & 91.6 & $60-80$ & 65.1 \\
\hline Softening point $\mathrm{T}_{\mathrm{R} \& \mathrm{~B}}\left({ }^{\circ} \mathrm{C}\right)$ & $\geq 45$ & 46.9 & $\geq 55$ & 61.0 \\
\hline Ductility $(\mathrm{cm})$ & $\geq 100\left(25^{\circ} \mathrm{C}\right)$ & $>150$ & $\geq 30\left(5^{\circ} \mathrm{C}\right)$ & $68.5\left(5^{\circ} \mathrm{C}\right)$ \\
\hline Elastic recovery & - & - & $\geq 65$ & 88 \\
\hline \multicolumn{5}{|c|}{ After TFOT } \\
\hline Mass loss (\%) & $\leq \pm 0.8$ & 0.38 & $\leq \pm 1.0$ & 0.22 \\
\hline Residual penetration ratio $\left(25^{\circ} \mathrm{C}, \%\right)$ & $\geq 57$ & 73.3 & $\geq 60$ & 66.9 \\
\hline Ductility $(\mathrm{cm})$ & $\geq 20\left(15^{\circ} \mathrm{C}\right)$ & $>120\left(15^{\circ} \mathrm{C}\right)$ & $\geq 20\left(5^{\circ} \mathrm{C}\right)$ & $33.2\left(5^{\circ} \mathrm{C}\right)$ \\
\hline
\end{tabular}

Table 2. Properties of rubber particles.

\begin{tabular}{ccccccc}
\hline Properties & $\begin{array}{c}\text { Density } \\
\left(\mathrm{g} / \mathrm{cm}^{3}\right)\end{array}$ & $\begin{array}{c}\text { Water } \\
\text { Content (\%) }\end{array}$ & $\begin{array}{c}\text { Metal } \\
\text { Content (\%) }\end{array}$ & $\begin{array}{c}\text { Fiber } \\
\text { Content (\%) }\end{array}$ & $\begin{array}{c}\text { Ash } \\
\text { Content (\%) }\end{array}$ & $\begin{array}{c}\text { Carbon Black } \\
\text { Content (\%) }\end{array}$ \\
\hline Value & 1.21 & 0.62 & 0.031 & 0.63 & 5.2 & 47 \\
\hline
\end{tabular}

Table 3. Diatomite composition.

\begin{tabular}{cccccccc}
\hline Composition & $\mathrm{SiO}_{2}$ & $\mathrm{Al}_{2} \mathrm{O}_{3}$ & $\mathrm{Fe}_{2} \mathrm{O}_{3}$ & $\mathrm{CaO}$ & $\mathrm{MgO}$ & $\mathrm{TiO}_{2}$ & $\mathrm{~K}_{2} \mathrm{O}$ \\
\hline Ratio (\%) & 85.50 & 4.40 & 1.40 & 0.53 & 0.46 & 0.31 & 0.66 \\
\hline
\end{tabular}

Table 4. Group number and asphalt-aggregate ratios.

\begin{tabular}{ccccc}
\hline \multirow{2}{*}{ Gradation } & \multicolumn{4}{c}{ Asphalt Types } \\
\cline { 2 - 5 } & Base Asphalt & $\begin{array}{c}\text { Diatomite and Crumb } \\
\text { Rubber Particles } \\
\text { + Base Asphalt }\end{array}$ & $\begin{array}{c}\text { SBS Modified } \\
\text { Asphalt }\end{array}$ & $\begin{array}{c}\text { Diatomite and Crumb } \\
\text { Rubber Particles } \\
\text { + SBS Modified Asphalt }\end{array}$ \\
\hline AC-13 & AC (4.8\%) & DRAC (5.4\%) & SAC (4.9\%) & SDRAC (5.5\%) \\
SMA-13 & SMA (5.3\%) & DRSMA (5.9\%) & SSMA (5.5\%) & SDRSMA (6.1\%) \\
\hline
\end{tabular}

Note: The content in brackets in the table is the asphalt-aggregate ratio.

Table 5. Properties of basalt aggregate.

\begin{tabular}{cccccc}
\hline \multicolumn{2}{c}{ Coarse Aggregate } & & \multicolumn{2}{c}{ Fine Aggregate } \\
\hline Properties & Standard & Value & Properties & Standard & Value \\
\hline weared stone value (\%) & $\leq 28$ & 20.9 & apparent specific gravity & $\geq 2.5$ & 2.733 \\
Crush stone value $(\%)$ & $\leq 26$ & 18.6 & Water absorption (\%) & - & 0.65 \\
Soundness of aggregate by use of Sodium & $\leq 12$ & 6 & angularity value (s) & $\geq 30$ & 38.9 \\
sulfate (\%) & $\leq 15$ & 9.7 & Sand equivalent (\%) & $\geq 60$ & 66 \\
\hline Elongated particle contents (\%) & & & &
\end{tabular}




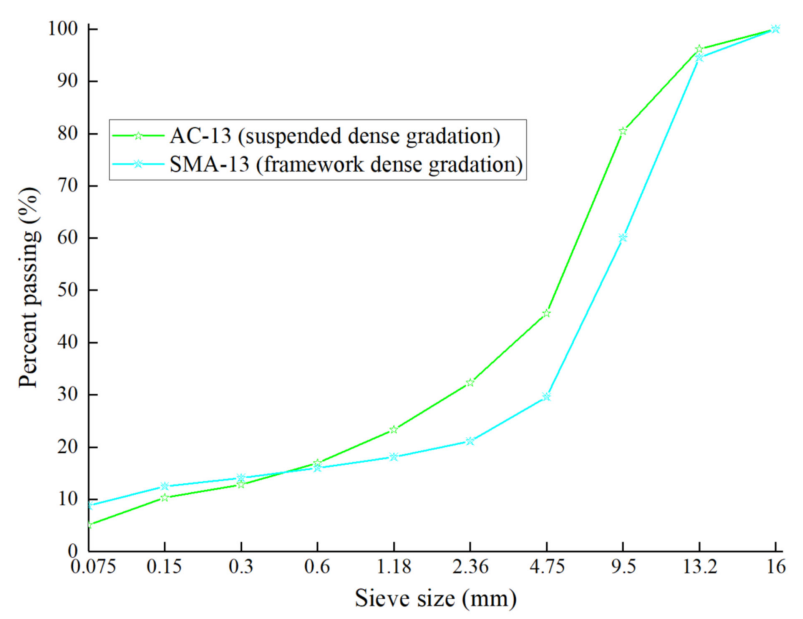

Figure 1. Aggregate gradation.

\subsection{Experimental Method}

The properties of eight types of asphalt mixtures were evaluated according to JTG E20-2011 [21].

\subsubsection{Rutting Tests}

The rutting tests at $60{ }^{\circ} \mathrm{C}$ were conducted to study the high-temperature permanent deformation resistance of eight types of asphalt mixtures. The rutting slabs (length: $300 \mathrm{~mm}$, width: $300 \mathrm{~mm}$ and height: $50 \mathrm{~mm}$ ) were conditioned at $60^{\circ} \mathrm{C} \pm 0.5^{\circ} \mathrm{C}$ for $5 \mathrm{~h}$ before the rutting tests, as shown in Figure 2. The rolling speed of the rubber wheel for the rutting tests was $42 \pm 1$ times/min, and the load was 0.7 MPa. The dynamic stability (DS) used to evaluate the high-temperature stability of asphalt mixtures could be calculated by Equation (1) [25].

$$
D S=\frac{\left(t_{2}-t_{1}\right) \times N}{d_{2}-d_{1}}=\frac{15 \times 42}{d_{2}-d_{1}},
$$

where $N$ is the rolling speed of the wheel, 42 times/min and $d_{1}$ and $d_{2}$ are the rutting depth at $t_{1}(45 \mathrm{~min})$ and $t_{2}(60 \mathrm{~min})$, respectively, $\mathrm{mm}$.

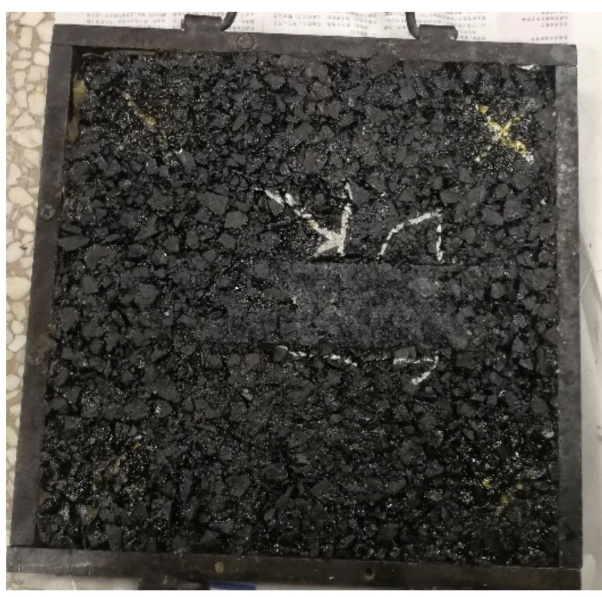

(a)

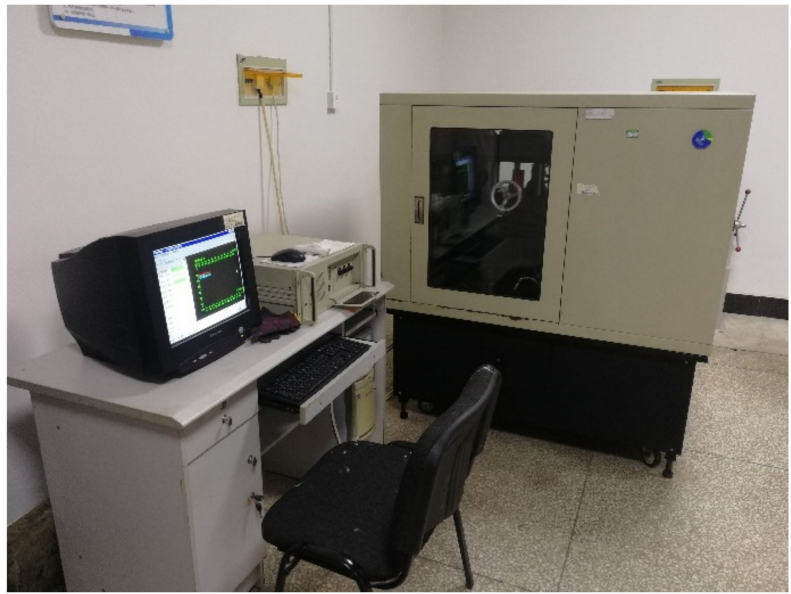

(b)

Figure 2. The rutting tests at $60^{\circ} \mathrm{C}$ : (a) rutting slab and (b) rutting tests. 


\subsubsection{Low-Temperature Trabecular Bending Tests}

The trabecular bending tests at $-10{ }^{\circ} \mathrm{C}$ were performed to analyze the anti-crack ability of eight types of asphalt mixtures at low-temperature. For the trabecular bending tests, a contact pressure with $50 \mathrm{~mm} / \mathrm{min}$ was loaded on the beam specimens with a size of $250 \mathrm{~mm}$ by $30 \mathrm{~mm}$ by $35 \mathrm{~mm}$ after $2 \mathrm{~h}$ under $-10^{\circ} \mathrm{C}$, as shown in Figure 3. The maximum bending-tensile failure strength $\left(R_{B}\right)$, the maximum bending-tensile failure strain $\left(\varepsilon_{B}\right)$, and the bending-tensile failure stiffness modulus $\left(S_{B}\right)$ for low-temperature trabecular bending tests were calculated by Equations (2)-(4) [25].

$$
\begin{gathered}
R_{B}=\frac{3 \times L \times P_{B}}{2 \times b \times h^{2}}, \\
\varepsilon_{B}=\frac{6 \times h \times d}{L^{2}}, \\
S_{B}=\frac{R_{B}}{\varepsilon_{B}},
\end{gathered}
$$

where $P_{B}$ is the maximum bending-tensile failure force, $N ; L$ is the spanning length for the trabecular bending tests, $200 \mathrm{~mm}$; $h$ and $b$ are the height and width of the beam in the middle of the span, which need to be measured before the test, $\mathrm{mm}$; and $d$ is the deflection of the beam in the middle of the span when the sample were broken, $\mathrm{mm}$.

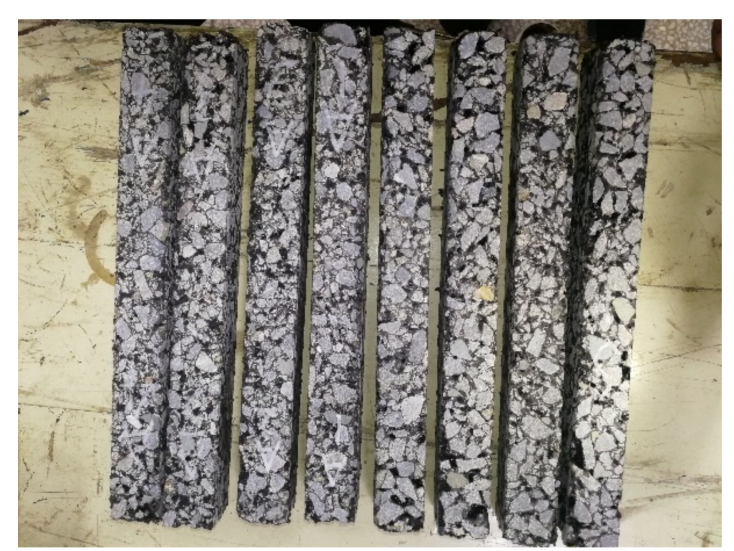

(a)

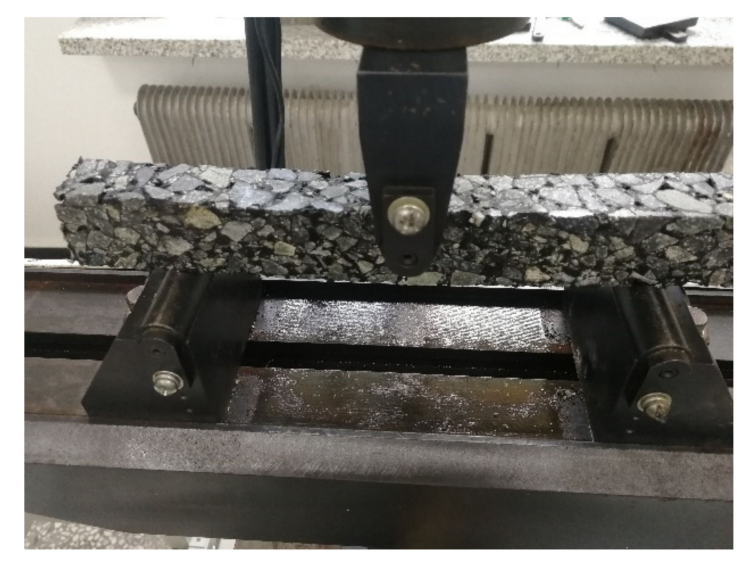

(b)

Figure 3. The trabecular bending tests at $-10^{\circ} \mathrm{C}$ : (a) beam specimens and (b) trabecular bending tests.

\subsubsection{Freeze-Thaw Splitting Test}

Freeze-thaw splitting tests were performed to study the water damage resistance of eight types of asphalt mixtures. In the freeze-thaw process, the cylindrical specimens $(100 \mathrm{~mm}$ in diameter, $63.5 \mathrm{~mm}$ in height) were vacuum watered, then the specimens were placed at $-18{ }^{\circ} \mathrm{C} \pm 2{ }^{\circ} \mathrm{C}$ for $16 \mathrm{~h}$, then the specimens were taken out and immediately placed in a water bath at $60^{\circ} \mathrm{C} \pm 0.5^{\circ} \mathrm{C}$ for $24 \mathrm{~h}$. Subsequently, the splitting strength of the samples undergoing freeze-thaw cycle and without freeze-thaw cycle was tested at $25^{\circ} \mathrm{C}$ for $2 \mathrm{~h}$ at the loading rate of $50 \mathrm{~mm} / \mathrm{min}$, as shown in Figure 4 . The tensile strength ratio (TSR) applied to evaluate the moisture susceptibility of asphalt mixtures was calculated according to Equation (5) [19].

$$
T S R=\frac{R_{T 2}}{R_{T 1}} \times 100,
$$

where $R_{T 2}$ and $R_{T 1}$ are the average splitting-tensile strength of undergoing freeze-thaw cycle and without freeze-thaw cycle, respectively, MPa. 


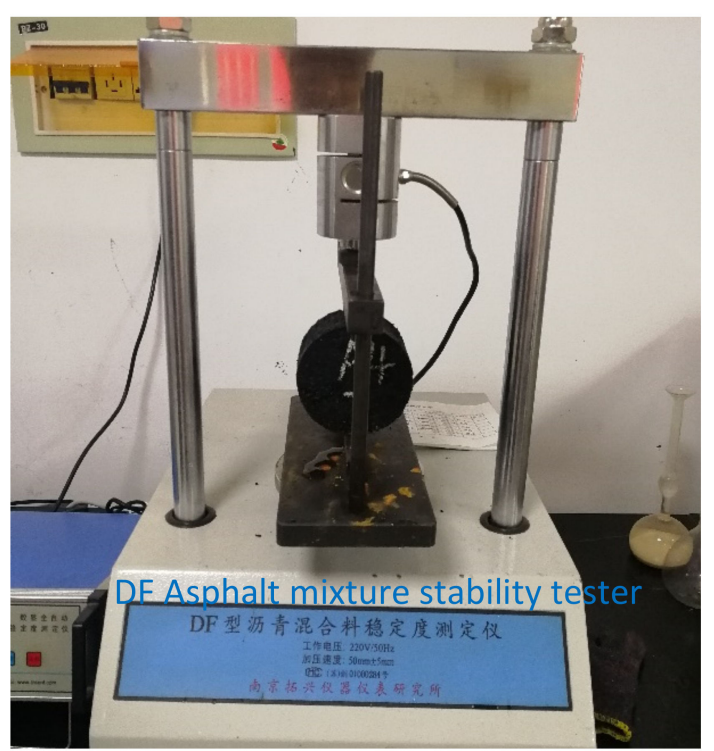

Figure 4. Splitting Test.

\subsubsection{Uniaxial Compression Creep Test}

The creep tests were conducted to test the viscoelastic response of eight kinds of asphalt mixtures under axial load and evaluate the effect of diatomite and rubber particles on the viscoelastic properties of asphalt mixtures, as shown in Figure 5. The tests were carried out on Cooper tester, the preload was $15 \mathrm{KPa}$, lasting for $30 \mathrm{~s}$; and the test load was $200 \mathrm{KPa}$ with a duration of $3600 \mathrm{~s}$. The test temperature was $20^{\circ} \mathrm{C}$ and the specimens were kept for $4 \mathrm{~h}$ before the test [26]. According to the tests, the variation of creep compliance of eight types of asphalt mixtures with loading time was obtained.

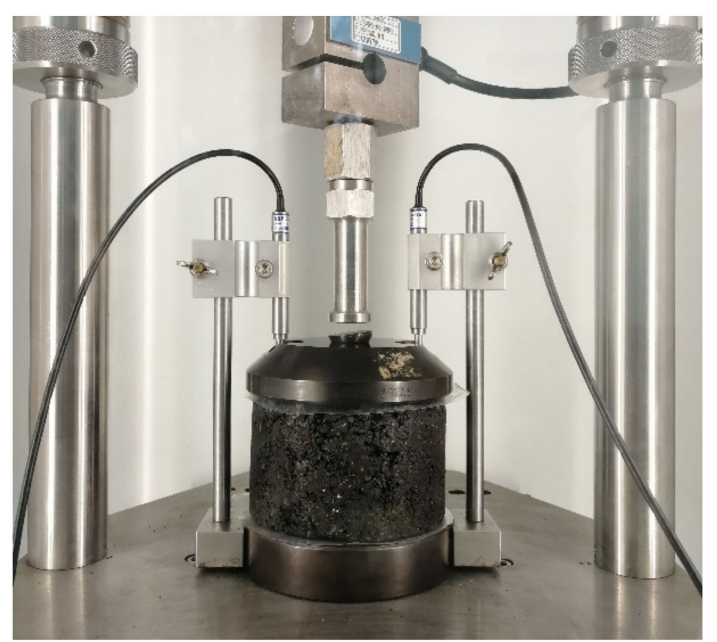

Figure 5. Uniaxial compression creep test.

\subsection{Interconversion between Creep Compliance and Relaxation Modulus}

The relationship between the creep compliance $J(t)$ and the relaxation modulus $S(t)$ for the asphalt or asphalt mixtures has been deducted in some studies, as shown in Equation (6) [26-28].

$$
\sum_{i=1}^{n} S\left(\frac{t_{i-1}+t_{i}}{2}\right) \times \frac{t_{i}-t_{i-1}}{6}\left[J\left(t_{n}-t_{i-1}\right)+4 J\left(t_{n}-\frac{t_{i-1}+t_{i}}{2}\right)+J\left(t_{n}-t_{i}\right)\right]=t_{n}
$$


where $t$ is the loading time. The loading time $t$ is divided into $n$ equal parts. $t_{n}$ is the $n$-th point in time. $t_{i}$ and $t_{i-1}$ are the $i$-th and $(i-1)$-th time points, respectively. Equation (6) can be written in the matrix, as shown in Equation (7).

$$
A x=B,
$$

where $A$, a lower-triangular matrix, can be expressed by Equation (8), and vector $x$ is the relaxation modulus need to be solved, which can be expressed by Equation (9).

$$
\begin{gathered}
A_{i j}= \begin{cases}\left(t_{i}-t_{i-1}\right)\left[J\left(t_{n}-t_{i-1}\right)+4 J\left(t_{n}-\frac{t_{i-1}+t_{i}}{2}\right)+J\left(t_{n}-t_{i}\right)\right], & \text { if } j \leq i \\
0, & \text { if } j>i\end{cases} \\
x_{i}=S\left(\frac{t_{i-1}+t_{i}}{2}\right), \\
B=6 t_{i},
\end{gathered}
$$

where $i, j \in\{1,2, \cdots, n\}$.

\section{Results and Discussion}

\subsection{Mechanical Properties of Asphalt Mixtures Modified by Diatomite and Crumb Rubber Particles}

\subsubsection{High-Temperature Stability}

Figure 6a shows the DS of the eight groups of asphalt mixtures. It can be found that SBS modified asphalt mixtures have higher DS compared with the base asphalt mixtures, which implies that the high-temperature resistance to permanent deformation of compound modified asphalt mixture can be improved by using the SBS modified asphalt as the binder.

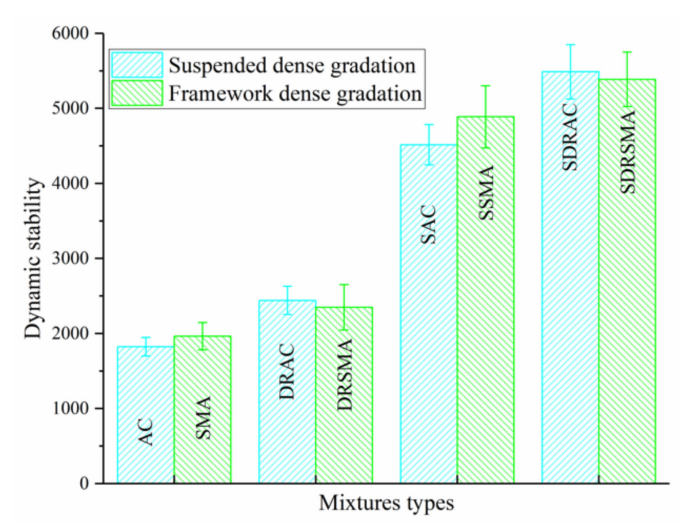

(a)

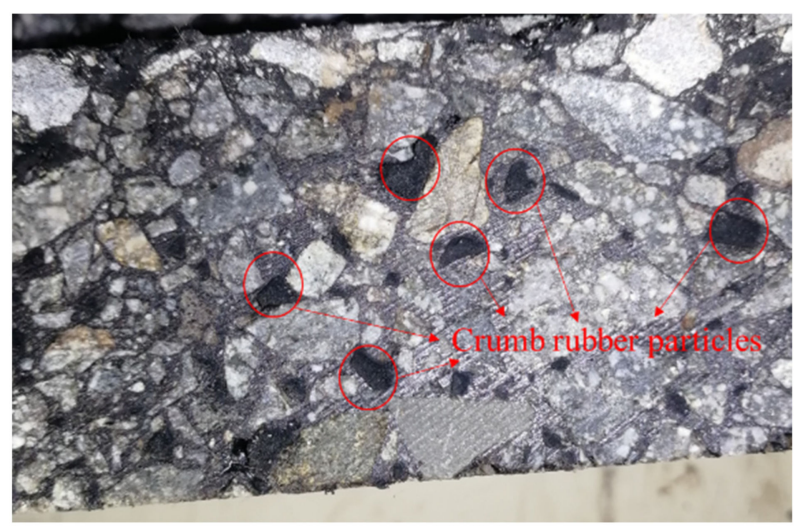

(b)

Figure 6. Test results of the high-temperature performance of asphalt mixtures: (a) DS results and (b) cross section of DRSMA.

Moreover, it can be seen from Figure 6a that the DS of the framework dense asphalt mixtures is greater than that of suspension dense asphalt mixtures when matrix asphalt or SBS modified asphalt is used as a binder. However, this conclusion will be opposite after adding diatomite and rubber particles, indicating that the compound modified asphalt mixture with suspended dense gradation has better high-temperature performance, which is mainly because the addition of rubber particles with larger particle size and softer texture has an adverse effect on the framework embedding effect of framework dense asphalt mixtures. 
In addition, comparing the base asphalt mixture, the composite modified asphalt mixture, and the SBS modified asphalt mixture, it can be seen that the DS of DRAC (diatomite and rubber particles modified asphalt mixtures with suspended dense gradation) is $33.84 \%$ higher than that of AC (base asphalt mixtures with suspended dense gradation), and the DS of DRSMA (diatomite and rubber particles modified asphalt mixtures with framework dense gradation) is $19.58 \%$ higher than that of SMA (base asphalt mixtures with framework dense gradation). Although adding diatomite and rubber particles can improve the high-temperature performance of the asphalt mixture to a certain extent, there is still a certain gap compared with the modification effect of SBS. The addition of rubber particles and diatomite can absorb a large amount of free asphalt in the asphalt mixture and increase the relative proportion of structural asphalt. The rubber particles, as a relatively soft elastomer, are filled into the asphalt mixture. Some local weak areas are introduced in the material (as shown in Figure 6b), so its advantage in improving the high-temperature performance of the asphalt mixture is not obvious.

\subsubsection{Anti-Crack at Low Temperature}

Figure 7 shows the calculation results of $R_{B}, \varepsilon_{B}$, and $S_{B}$ of eight groups of asphalt mixture. It can be seen from Figure 7 that the framework dense asphalt mixtures have higher $R_{B}, \varepsilon_{B}$, and $S_{B}$ than the suspended dense asphalt mixture. From the perspective of $\varepsilon_{B}$, it can be seen that the framework dense asphalt mixtures have better resistance to low temperature cracking than suspension dense asphalt mixtures. Comparing the test data of AC and DRAC or SMA and DRSMA, it can be seen that the addition of diatomite and rubber particles can increase the bending tensile failure strain of the asphalt mixture, reduce the bending stiffness modulus, and improve the bending tensile strength of the asphalt mixture. The addition of diatomite and rubber particles can improve the flexibility of asphalt mixture, furthermore, improve the low-temperature crack resistance of asphalt mixture. In addition, it can be seen that the performance improvement of asphalt mixtures by adding diatomite and rubber particles is still a little different from SBS modifier comparing with SAC (SBS modified asphalt mixtures with suspended dense gradation) and DRAC or SSMA (SBS modified asphalt mixtures with framework dense gradation) and DRSMA data. The diatomite and rubber particles are mainly used to strengthen the asphalt mixture by physical blending, which is weaker than SBS chemical modification. Moreover, as easily deformed particles, rubber particles will form a local weak area in the asphalt mixture, which will have a negative impact on the mechanical performance of asphalt mixtures enhanced by diatomite. Comparing the data of SDRSMA (SBS reinforced DRSMA), SDRAC (SBS reinforced DRAC), and other experimental groups, it can be seen that the diatomite and rubber particle compound modified asphalt mixtures used SBS modified asphalt as a binder has a better low-temperature cracking resistance, but it will also increase the economic cost to a certain extent.

Comparing the test data of different gradations, it can be found that the maximum flexural strain of DRAC and SDRAC is increased by $23.83 \%$ and $10.58 \%$ compared with AC and SAC, respectively, while the maximum tensile strain of DRSMA and SDRSMA is increased by $12.55 \%$ and $5.09 \%$, respectively, compared with SMA and SSMA. This shows that diatomite and rubber particles can improve the low-temperature performance of suspended dense asphalt mixtures better than the improvement of the low-temperature anti-cracking performance of framework dense asphalt mixtures, which is mainly attributable to the fact that the gradation of the dense-framed mixture SMA is highly dependent on the mineral material. The addition of rubber particles will affect the skeletal structure of the SMA during the fabricating process. Therefore, the rubber particles have a greater adverse effect on the mechanical properties of the SMA-graded asphalt mixture. 


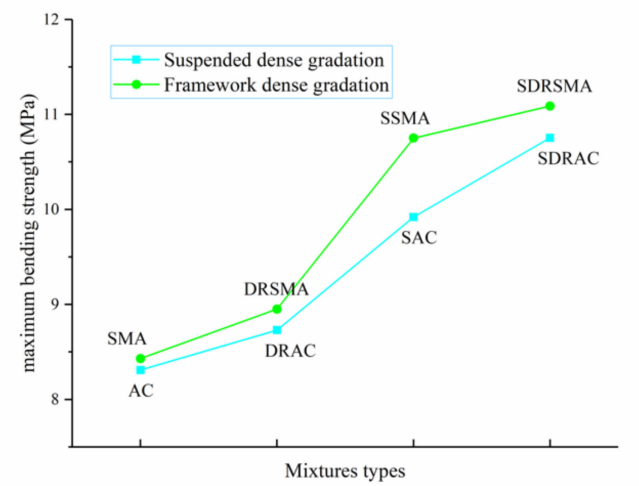

(a)

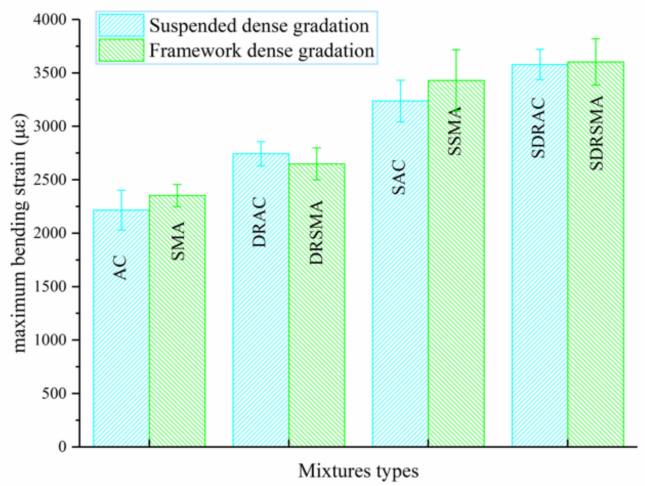

(b)

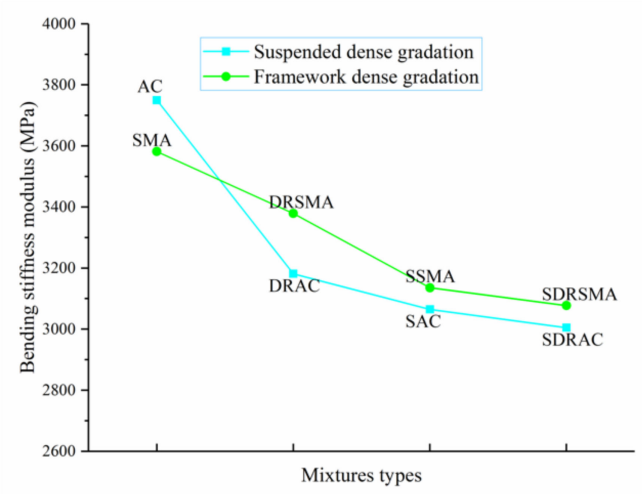

(c)

Figure 7. Test results of low-temperature performance of eight kinds of asphalt mixtures: (a) $R_{B} ;(\mathbf{b}) \varepsilon_{B}$; and (c) $S_{B}$.

\subsubsection{Moisture Susceptibility}

The specification (JTG F40-2004) stipulated that the asphalt mixture has good water stability when TSR is more than $80 \%$. Table 6 shows the calculation results of the freeze-thaw splitting tests. It can be seen from Table 6 that diatomite and rubber modified asphalt mixtures have good water stability. Comparing different types of modified asphalt mixtures, it can be found that the addition of diatomite and rubber particles will reduce the freeze-thaw splitting strength of the asphalt mixture. It has a negative impact on the water stability of the asphalt mixtures, which may be due to the fact that rubber particles are added into the asphalt mixture as an elastomer. After rotary compaction fabrication, the rubber particles in the asphalt mixture will be in an extruded state, with a certain degree of internal stress. The combination of this internal stress and the expansion force generated by water freezing increases the damage to the asphalt mixture, which will reduce the water stability of the asphalt mixture.

Table 6. Test results of freeze-thaw splitting tests.

\begin{tabular}{ccccccccc}
\hline \multirow{2}{*}{ Mixture } & \multicolumn{7}{c}{ Asphalt Mixture Types } \\
\cline { 2 - 8 } & AC & DRAC & SAC & SDRAC & SMA & DRSMA & SSMA & SDRSMA \\
\hline $\mathrm{R}_{\mathrm{T} 1}(\mathrm{MPa})$ & 0.816 & 0.885 & 1.0867 & 1.228 & 0.857 & 0.894 & 1.187 & 1.216 \\
$\mathrm{R}_{\mathrm{T} 2}(\mathrm{MPa})$ & 0.724 & 0.745 & 1.036 & 1.151 & 0.764 & 0.775 & 1.135 & 1.153 \\
$\mathrm{TSR}(\%)$ & 88.7 & 84.2 & 95.3 & 93.7 & 89.2 & 86.7 & 95.6 & 94.8 \\
\hline
\end{tabular}

Comparing the test data of diatomite and rubber particle compound modified asphalt mixture and base asphalt mixture or SBS + diatomite and rubber particle composite modified asphalt mixture and SBS modified asphalt mixture, it can be found that using SBS modified asphalt as binder has better 
water stability in diatomite and rubber particle composite modified asphalt mixture than using matrix asphalt. Plus, the negative impact of rubber particles on water stability is relatively weak when using SBS modified asphalt. SBS modified asphalt mixture has strong cohesiveness and can well limit the damage caused by the internal stress of rubber particles and the frost heave force of water, which will reduce the damage rate of the asphalt mixture.

By comparing the TSR data of two kinds of graded asphalt mixture, it can be found that the TSR of the asphalt mixtures with skeleton dense gradation is higher than that of the suspension dense asphalt mixture, and the composite modified asphalt mixture of diatomite and rubber particles also has higher TSR and better water stability. This may be due to the higher asphalt aggregate ratio of skeleton dense asphalt mixture with a better binding effect on aggregate and rubber particles, and the porosity is relatively small, which makes it difficult for external water to enter the internal voids of the asphalt mixture and the interface between asphalt and aggregate or rubber particles, thus improving the water stability of asphalt mixture.

\subsection{Creep Characteristics of Asphalt Mixtures}

\subsubsection{Test Results of Creep Compliance}

According to the creep tests, the creep compliances of eight groups of asphalt mixtures with three samples per group were tested and calculated at $20^{\circ} \mathrm{C}$. The average results are shown in Figure 8 . It can be seen from Figure 8 that with the increase of loading time, the creep flexibility of the eight asphalt mixtures increases rapidly at first and then slowly. Moreover, compared with the matrix asphalt mixture, the addition of diatomite and rubber particles can improve the creep compliance of asphalt mixture, but the improved range is lower than that of SBS modified asphalt mixture. However, the use of SBS modified asphalt as a binder to prepare diatomite and rubber particle composite modified asphalt mixtures will have better anti-creep deformation ability. Furthermore, the skeleton dense asphalt mixture has smaller creep compliance, and the composite modified asphalt mixture with skeleton dense gradation will have better anti-creep deformation ability.

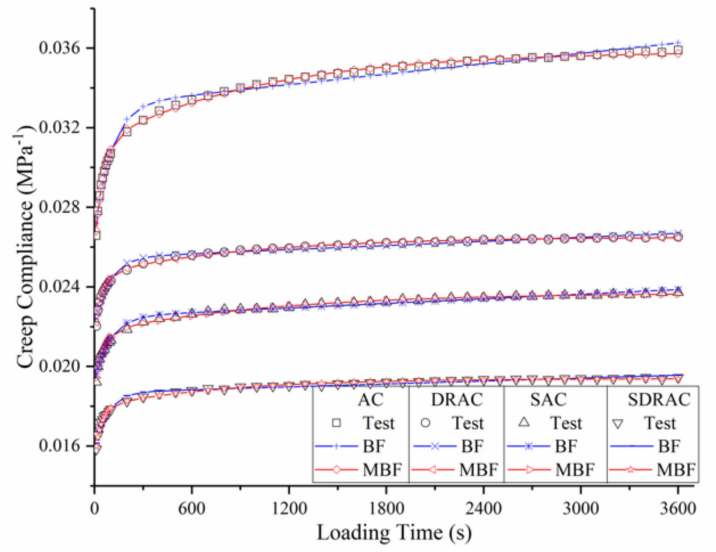

(a)

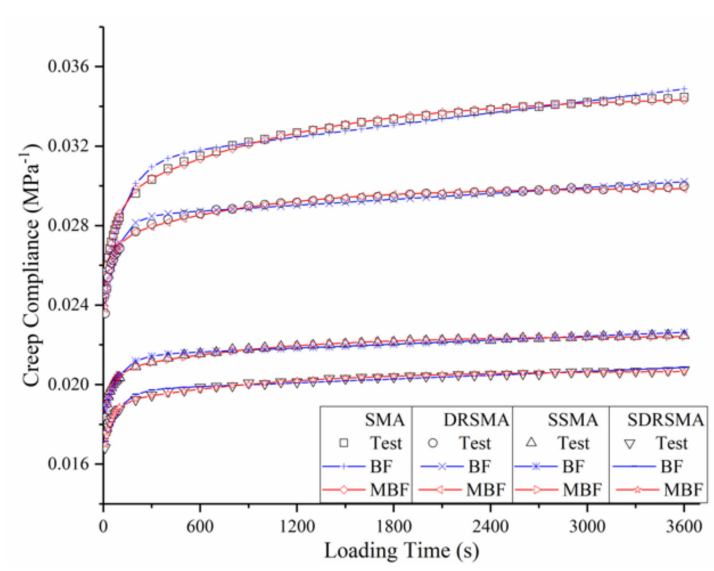

(b)

Figure 8. Creep compliance test results: (a) suspended dense gradation and (b) framework dense gradation.

\subsubsection{Fitting Analyses of Creep Compliance}

To further quantitatively analyze the effect of diatomite and rubber particles on the creep characteristics of asphalt mixtures, Burgers model and modified Burgers model were adopted to fit 
the curve of the creep compliance $(J(t))$. The Burgers model and the modified Burgers are shown in Equations (12) and (13), respectively [27-30].

$$
\begin{gathered}
J(t)=\frac{1}{E_{1}}+\frac{t}{\eta_{1}}+\frac{1}{E_{2}}\left[1-\exp \left(-\frac{E_{2} t}{\eta_{2}}\right)\right], \\
J(t)=\frac{\varepsilon}{\sigma}=\frac{1}{E_{1}}+\frac{1}{A B}\left(1-e^{-B t}\right)+\frac{1}{E_{2}}\left(1-e^{-\frac{E_{2}}{\eta_{2}} t}\right), \\
\operatorname{Min} F=\frac{1}{N} \sqrt{\sum_{i=1}^{n}\left[\left(J\left(t_{i}\right)-J^{\prime}\left(t_{i}\right)\right) / J\left(t_{i}\right)\right]^{2}},
\end{gathered}
$$

The Burgers model is composed of a Maxwell model and a Kelvin model in series. $E_{1}$ and $\eta_{1}$ are the elastic modulus and the viscosity coefficient of the Maxwell model, respectively, and $E_{2}$ and $\eta_{2}$ are the elastic modulus and the viscosity coefficient of the Kelvin model, respectively. The modified Burgers model is to replace a sticky pot in Burgers with a sticky pot with consolidation effect, that is, $\mathrm{t} / \eta_{1}$ is replaced by $\left(1-e^{-B t}\right) /(A B)$, and $A$ and $B$ are the parameters to be fitted. When the loading time tends to infinity, the creep deformation of the asphalt mixture can be calculated by Equation (15).

$$
\Delta L=\sigma_{0} J_{\infty} L=\left(1 / E_{1}+1 /(A B)+1 / E_{2}\right) \sigma_{0} L,
$$

where $\sigma_{0} L / E_{1}$ is the instantaneous elastic deformation, $E_{1}$ can reflect the ability of the asphalt mixture to resistance instantaneous elastic deformation, $\sigma_{0} L / E_{2}$ is the viscoelastic deformation, $E_{2}$ can reflect the ability of the asphalt mixture to resistance viscoelastic deformation; $\sigma_{0} L /(A B)$ is the unrecoverable viscous deformation, and $A B$ can reflect the ability of asphalt mixture to resist irreversible permanent deformation.

According to the creep flexibility of eight groups of asphalt mixtures shown in Figure 8, the parameters of Burgers model and modified Burgers model were solved by EXCEL software, and the solution method is shown in Equation (14). The solution results of the parameters are shown in Table 7, and the comparison between the solution results of the two models and the experimental results is shown in Figure 8. From the $\mathrm{R}^{2}$ of Table 7 and the comparison diagram of Figure 8, we can see that both the Burgers model and the modified Burgers model can better reflect the creep flexibility of asphalt mixtures. When describing the change of creep flexibility of eight groups of asphalt mixtures, the modified Burgers model is better than the Burgers model. Asphalt mixture tends to converge in the later stage of creep deformation, so it is difficult to be described by Burgers model.

Table 7. Parameter calculation results of Burgers model and modified Burgers model.

\begin{tabular}{ccccccccc}
\hline \multirow{2}{*}{ Parameters } & \multicolumn{7}{c}{ Asphalt Mixture Types } \\
\cline { 2 - 9 } & AC & DRAC & SAC & SDRAC & SMA & DRSMA & SSMA & SDRSMA \\
\hline$E_{1}(\mathrm{MPa})$ & 37.64 & 45.40 & 51.87 & 63.35 & 40.43 & 42.53 & 54.55 & 59.48 \\
$\eta_{1}(\mathrm{MPa} \cdot \mathrm{s})$ & $1,144,973$ & $2,905,223$ & $2,605,226$ & $4,080,010$ & 995,060 & $2,025,960$ & $3,006,142$ & $3,105,033$ \\
$E_{2}(\mathrm{MPa})$ & 152.60 & 290.97 & 311.97 & 344.94 & 153.31 & 203.13 & 321.60 & 345.53 \\
$\eta_{2}(\mathrm{MPa} \cdot \mathrm{s})$ & 15,099 & 24,906 & $28,615.28$ & 25,735 & 19,290 & 15,868 & $27,903.37$ & 28,416 \\
$\mathrm{R}^{2}$ & 0.9874 & 0.9870 & 0.9869 & 0.9849 & 0.9902 & 0.9854 & 0.9865 & 0.9864 \\
\hline$E_{1}(\mathrm{MPa})$ & 38.75 & 46.18 & 52.79 & 64.89 & 41.63 & 43.73 & 55.70 & 60.64 \\
$A$ & 9292 & 16,249 & 18,766 & 15,714 & 12,014 & 9522 & 17,192 & 18,361 \\
$\mathrm{~B}$ & 0.0200 & 0.0207 & 0.0194 & 0.0250 & 0.0161 & 0.0246 & 0.0220 & 0.0217 \\
$E_{2}(\mathrm{MPa})$ & 213.49 & 527.71 & 495.59 & 692.21 & 186.10 & 361.31 & 539.91 & 586.58 \\
$\eta_{2}(\mathrm{MPa} \cdot \mathrm{s})$ & 216,198 & 492,349 & 534,803 & 539,234 & 214,929 & 309,185 & 486,910 & 586,547 \\
$\mathrm{R}^{2}$ & 0.9981 & 0.9956 & 0.9953 & 0.9947 & 0.9983 & 0.9956 & 0.9966 & 0.9959 \\
$\mathrm{AB}$ & 185.84 & 336.35 & 364.06 & 392.85 & 193.43 & 234.24 & 378.22 & 398.43 \\
\hline
\end{tabular}


The solution results of the Burgers model show adding rubber particles and diatomite can increase the instantaneous elastic modulus $E_{1}$ and viscosity coefficient $\eta_{1}$ of the matrix asphalt mixture, which shows that the ability of the asphalt mixture to resist instantaneous elastic deformation and the ability to resist permanent deformation under load can be improved by adding diatomite and rubber particles. Comparing the fitting results of different gradations, it can be found that the improvement effect of diatomite and rubber particles on the suspended dense asphalt mixture is greater than that of the skeleton dense asphalt mixture. This is mainly due to the adverse effect of the addition of rubber particles on the skeleton embedding effect of the dense skeleton asphalt mixture.

From the perspective of different asphalt binders, it can be seen that when SBS modified asphalt is used as a binder, as the improvement of diatomite the resistance of diatomaceous earth and rubber particles to the asphalt mixture against instantaneous elastic deformation and the ability to resist permanent deformation are more obvious. The SBS modified asphalt with higher binding capacity can promote the enhancement of diatomite and rubber particles.

It can be found from the parameters of the modified Burgers model that the result of the instantaneous elastic modulus is close to that of Burgers and has the same changing trend. It can be seen from the fitting results of $E_{2}$ and $A B$ that adding the diatomite and rubber particles can improve the resistance viscoelastic deformation and irreversible permanent deformation of the asphalt mixture, and the improvement effect of the suspended dense matrix asphalt mixture is higher than that of the skeleton dense matrix asphalt mixture.

\subsection{Relaxation Characteristics of Asphalt Mixtures}

\subsubsection{Calculation of Relaxation Modulus}

According to Equation (6), the MATLAB software was used to calculate the relaxation moduli of the eight groups of asphalt mixtures. Figure 9 shows the results of the relaxation moduli for the eight groups of asphalt mixtures. It can be found from Figure 9 that with the increase of loading time, the relaxation modulus of the eight asphalt mixtures declines rapidly at first and then declines slowly.

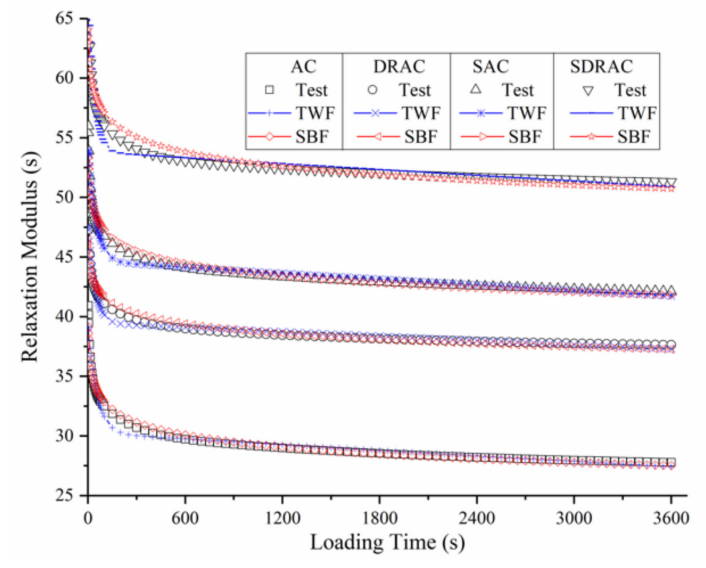

(a)

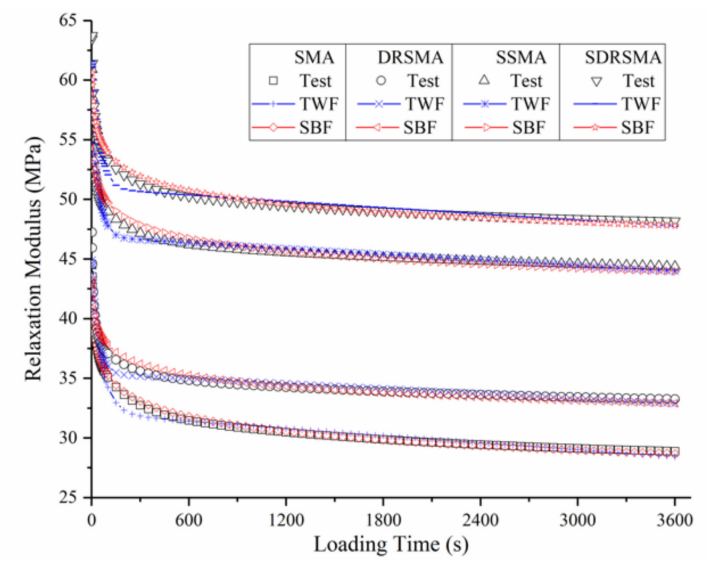

(b)

Figure 9. Relaxation moduli test results: (a) suspended dense gradation and (b) framework dense gradation.

Adding diatomite and rubber particles can elevate the relaxation modulus of the asphalt mixture compared with the neat asphalt mixture. The rubber particle and diatomite compound modified asphalt mixtures prepared by using SBS modified asphalt as a binder will have better stress relaxation capabilities. Plus, it can be found that the skeleton dense asphalt mixtures have a larger relaxation modulus than the suspended dense asphalt mixtures, and the composite modified asphalt mixture using the skeleton dense gradation will have better stress relaxation characteristics. 


\subsubsection{Fitting Analysis of Relaxation Modulus}

To analyze the relaxation properties of the eight groups of asphalt mixtures, the second-order extensive Maxwell model and the Scott-Blair model were applied to analyze the relaxation moduli $E(t)$ of the eight types of asphalt mixtures with time. The expressions of the second-order extensive Maxwell model [31-34] and the Scott-Blair model [35,36] are shown in Equations (16) and (17), respectively.

$$
E(t)=E_{1} e^{-t / \rho_{1}}+E_{2} e^{-t / \rho_{2}},
$$

where $E_{1}$ and $E_{2}$ are the strengths to characterize the stress relaxation $\rho_{1}$ and $\rho_{2}$ are the relaxation times used to characterize the stress relaxation ability of asphalt mixtures.

$$
E(t)=\eta \frac{t^{-\alpha}}{\int_{0}^{1-\alpha} e^{-\tau} \tau^{-\alpha} d \tau}
$$

where $\eta$ is the viscous damping coefficient, $\mathrm{MPa} \cdot \mathrm{s}$, and $\alpha$ is a fractional order, which can be used to analyze the stress relaxation process of asphalt mixtures. The larger the value is, the closer the material property is to the rheological property of fluid, and the smaller the value is, the closer it is to the elastic property of solid.

The unknown parameters of Equations (16) and (17) are solved by EXCEL software. The solution results of the two model parameters are shown in Table 8. From the correlation coefficient $R^{2}$ in Table 8 and the comparison diagram in Figure 9, we can see that the fitting curves of Scott-Blair model and second-order extended Maxwell model are in good agreement with the calculated results. This means that both the Scott-Blair model and the second-order extended Maxwell model can better describe the relaxation trend of eight groups of asphalt mixtures.

Table 8. Parameter calculation results of the second-order extensive Maxwell model and the Scott-Blair model.

\begin{tabular}{ccccccccc}
\hline \multirow{2}{*}{ Parameters } & \multicolumn{7}{c}{ Asphalt Mixture Types } \\
\cline { 2 - 8 } & AC & DRAC & SAC & SDRAC & SMA & DRSMA & SSMA & SDRSMA \\
\hline$E_{1}(\mathrm{MPa})$ & 30.237 & 39.483 & 44.639 & 53.825 & 32.043 & 35.408 & 46.865 & 50.913 \\
$E_{2}(\mathrm{MPa})$ & 9.407 & 8.863 & 9.921 & 14.024 & 10.511 & 10.324 & 11.335 & 11.385 \\
$\rho_{1}(\mathrm{~s})$ & 36,717 & 63,395 & 53,442 & 64,322 & 30,117 & 49,098 & 56,630 & 56,201 \\
$\rho_{2}(\mathrm{~s})$ & 53.847 & 39.806 & 46.885 & 35.649 & 65.801 & 36.844 & 41.031 & 45.090 \\
$\mathrm{R}^{2}$ & 0.9773 & 0.9609 & 0.9715 & 0.9608 & 0.9779 & 0.9689 & 0.9617 & 0.9702 \\
\hline$\eta$ & 42.631 & 49.023 & 56.532 & 67.768 & 47.683 & 46.236 & 59.382 & 64.181 \\
$\alpha$ & 0.04967 & 0.03117 & 0.03428 & 0.03291 & 0.05769 & 0.03865 & 0.03416 & 0.03350 \\
$\mathrm{R}^{2}$ & 0.9833 & 0.9397 & 0.9688 & 0.9153 & 0.9947 & 0.9384 & 0.9450 & 0.9627 \\
\hline
\end{tabular}

From the parameter calculation results of second-order extensive Maxwell model, the addition of rubber particle and diatomite can reduce the relaxation time of asphalt mixture, make the internal stress of asphalt mixture rapidly relax due to temperature change or external load, and then improve the stress relaxation ability of asphalt mixture. According to the results of the Scott-Blair model, it can be found that the addition of rubber particle and diatomite can reduce the fractional order $\alpha$ and increase the solid elastic properties of asphalt mixture, which means that the addition of rubber particles and diatomite can improve the elastic properties of asphalt mixture, the deformation can be recovered quickly after the load is removed, and the residual irrecoverable deformation will be reduced.

Comparing the test results of different modified bitumen, the improvement of rubber particle and diatomite on the relaxation modulus of asphalt mixture is weaker than that of SBS modified asphalt, and the joint use of diatomite, rubber particles, and SBS modified asphalt will make the asphalt mixture have the best relaxation characteristics. From the point of view of gradation, it can 
be seen that the improvement effect of diatomite and basalt fiber on the relaxation and solid elastic properties of suspended dense asphalt mixture is obviously better than that of skeleton dense asphalt mixture. The damage of rubber particles to the skeleton extrusion of skeleton dense asphalt mixture and the introduction of local weak areas also have an adverse effect on the relaxation characteristics of asphalt mixture.

From the parameter calculation results of second-order extensive Maxwell model, it can be seen that the addition of rubber particle and diatomite can reduce the relaxation stiffness of asphalt mixture, which can rapidly relax the internal stress caused by temperature change or external load in the asphalt mixtures, and then improve the stress relaxation ability of asphalt mixture. According to the results of the Scott-Blair model, it can be found that the addition of rubber particle and diatomite can reduce the fractional order $\alpha$ and increase the solid elastic properties of asphalt mixture, which means that the addition of rubber particle and diatomite can improve the elastic properties of asphalt mixtures, the deformation can be recovered quickly after the load is removed, and the residual irrecoverable deformation will be reduced.

Comparing the test results of different modified asphalt, it can be seen that the improvement effect of rubber particle and diatomite on the relaxation modulus of asphalt mixture is weaker than that of SBS modified asphalt. Furthermore, when diatomite, rubber particles, and SBS modified asphalt are used together, the asphalt mixture will have the best relaxation characteristics. From the point of view of gradation, it can be seen that the improvement effect of diatomite and basalt fiber on the relaxation and solid elastic properties of suspended dense asphalt mixture is obviously better than that of skeleton dense asphalt mixture. The damage of rubber particles to the skeleton extrusion of skeleton dense asphalt mixture and the introduction of local weak areas also have an adverse effect on the relaxation characteristics of asphalt mixture.

\section{Conclusions}

In this study, diatomite and crumb rubber particles were used to reinforce the properties of asphalt mixtures. According to the rutting test, low-temperature trabecular bending test, freeze-thaw splitting test, and uniaxial compression creep test, the effects of rubber particle and diatomite on the road performance and creep characteristics of asphalt mixtures were analyzed, and their creep characteristics were studied by the Burgers model and the modified Burgers model. Through the convolution integral and creep test data, the relaxation moduli of compound modified asphalt mixtures were calculated, and their relaxation characteristics were evaluated by using the second-order extensive Maxwell model and the Scott-Blair model. Based on the above analytical results, the following conclusions can be achieved:

(1) The addition of rubber particle and diatomite can improve the high temperature stability and low-temperature crack resistance of asphalt mixtures, but the improvement effect is weaker than that of SBS. This is because rubber particle and diatomite are mainly used for physical blending to strengthen asphalt mixture, and its effect is weaker than the chemical modification of SBS. Diatomite and rubber particles have a negative impact on the water stability of asphalt mixture, while the negative effect of rubber particles on water stability become relatively weak when using SBS modified asphalt. While when using SBS modified asphalt, the negative effect of rubber particles on water stability is relatively weak.

(2) The improvement effect of rubber particle and diatomite on the high and low temperature performance of suspended dense asphalt mixture is better than that of skeleton dense asphalt mixture. After the addition of rubber particles, the skeleton extrusion of skeleton dense asphalt mixture is destroyed and the local weak area is introduced, which can reduce the enhancement effect of rubber particle and diatomite on the high and low temperature performance of asphalt mixtures. 
(3) The addition of rubber particle and diatomite can improve the ability of instantaneous elastic deformation, viscoelastic deformation, and irreversible permanent deformation. SBS modified asphalt has high bonding performance which can promote the strengthening of rubber particle and diatomite. The improvement effect of suspended dense matrix asphalt mixture is higher than that of skeleton dense asphalt mixture.

(4) Diatomite and rubber particles can increase the relaxation modulus of asphalt mixtures, but the improvement effect is not as good as SBS modified asphalt; under the combined action of diatomaceous earth, rubber particles, and SBS modified asphalt mixture, the relaxation characteristics of asphalt mixture are the best. The effect of rubber particle and diatomite on the relaxation and solid elastic properties of the suspended dense asphalt mixture is obviously better than that of the skeleton dense asphalt mixture.

Author Contributions: Conceptualization, C.L. and Z.G.; methodology, C.L., Z.G. and H.Z.; validation, C.L., H.Z. and X.X.; formal analysis, H.Z.; investigation, J.H.; supervision, C.L.; writing-original draft preparation, H.Z.; writing-review and editing, C.L., Z.G., X.X. and J.H.; project administration, C.L.; funding acquisition, C.L. All authors have read and agreed to the published version of the manuscript.

Funding: This research was funded by the Science and Technology Project of Jilin Provincial High Class Highway Construction Bureau, Contract No. 2018ZDGC-9-1.

Acknowledgments: We gratefully acknowledge the financial support of the above project and the researchers of all reports cited in our paper.

Conflicts of Interest: The authors declare no conflict of interest.

\section{References}

1. Bressi, S.; Fiorentini, N.; Huang, J.; Losa, M. Crumb Rubber Modifier in Road Asphalt Pavements: State of the Art and Statistics. Coatings 2019, 9, 384. [CrossRef]

2. Jamrah, A.A.; Emin Kutay, M. Comparison of Linear Viscoelastic Properties of Crumb Rubber-Modified Binders Measured Using Parallel-Plate and Concentric Cylinder Geometries with Asphalt Mixture Dynamic Modulus. J. Mater. Civil. Eng. 2020, 32, 04019352. [CrossRef]

3. Venudharan, V.; Biligiri, K.P. Effect of crumb rubber gradation on asphalt binder modification: Rheological evaluation, optimization and selection. Mater. Struct. 2017, 50, 129. [CrossRef]

4. Wang, T.; Xiao, F.; Amirkhanian, S.; Huang, W.; Zheng, M. A review on low temperature performances of rubberized asphalt materials. Constr. Build. Mater. 2017, 145, 483-505. [CrossRef]

5. Daly, W.H.; Balamurugan, S.S.; Negulescu, I.; Akentuna, M.; Mohammad, L.; Cooper, S.B.; Cooper, S.B.; Baumgardner, G.L. Characterization of Crumb Rubber Modifiers after Dispersion in Asphalt Binders. Energy Fuels 2018, 33, 2665-2679. [CrossRef]

6. Wang, H.; You, Z.; Mills-Beale, J.; Hao, P. Laboratory evaluation on high temperature viscosity and low temperature stiffness of asphalt binder with high percent scrap tire rubber. Constr. Build. Mater. 2012, 26, 583-590. [CrossRef]

7. Abdul Hassan, N.; Abdulhussein Abdulridha Almusawi, A.; Zul Hanif Mahmud, M.; Asniza Mohamed Abdullah, N.; Athma Mohd Shukry, N.; Mashros, N.; Putra Jaya, R.M.D.; Yusoff, N.I. Engineering properties of crumb rubber modified dense-graded asphalt mixtures using dry process. IOP Conf. Ser. Earth Environ. Sci. 2019, 220, 012009. [CrossRef]

8. Zhang, F.; Hu, C. The research for crumb rubber/waste plastic compound modified asphalt. J. Therm. Anal. Calorim. 2015, 124, 729-741. [CrossRef]

9. Zhong, K.; Sun, M.; Chang, R. Performance evaluation of high-elastic/salt-storage asphalt mixture modified with Mafilon and rubber particles. Constr. Build. Mater. 2018, 193, 153-161. [CrossRef]

10. Behnood, A.; Olek, J. Rheological properties of asphalt binders modified with styrene-butadiene-styrene (SBS), ground tire rubber (GTR), or polyphosphoric acid (PPA). Constr. Build. Mater. 2017, 151, 464-478. [CrossRef] 
11. Behnood, A.; Olek, J. Stress-dependent behavior and rutting resistance of modified asphalt binders: An MSCR approach. Constr. Build. Mater. 2017, 157, 635-646. [CrossRef]

12. Qian, C.; Fan, W.; Yang, G.; Han, L.; Xing, B.; Lv, X. Influence of crumb rubber particle size and SBS structure on properties of CR/SBS composite modified asphalt. Constr. Build. Mater. 2020, 235, 117517. [CrossRef]

13. Wei, H.; He, Q.; Jiao, Y.; Chen, J.; Hu, M. Evaluation of anti-icing performance for crumb rubber and diatomite compound modified asphalt mixture. Constr. Build. Mater. 2016, 107, 109-116. [CrossRef]

14. Cheng, Y.; Li, L.; Zhang, Y.; Lv, Z.; Zhu, C. Quantitative Analysis of Effect and Interaction of Diatomite and Basalt Fiber on Asphalt Performance. J. Mater. Civil. Eng. 2019, 31, 04019306. [CrossRef]

15. Zhang, Y.B.; Zhu, H.Z.; Wang, G.A.; Chen, T.J. Evaluation of Low Temperature Performance for Diatomite Modified Asphalt Mixture. Adv. Mater. Res. 2011, 413, 246-251. [CrossRef]

16. Yang, C.; Xie, J.; Zhou, X.; Liu, Q.; Pang, L. Performance Evaluation and Improving Mechanisms of Diatomite-Modified Asphalt Mixture. Materials 2018, 11, 686. [CrossRef]

17. Tan, Y.Q.; Zhang, L.; Zhang, X.Y. Investigation of low-temperature properties of diatomite-modified asphalt mixtures. Constr. Build. Mater. 2012, 36, 787-795.

18. Cheng, Y.; Zhu, C.; Tan, G.; Lv, Z.; Yang, J.; Ma, J. Laboratory Study on Properties of Diatomite and Basalt Fiber Compound Modified Asphalt Mastic. Adv. Mater. Sci. Eng. 2017, 2017, 1-10. [CrossRef]

19. Cheng, Y.; Li, L.; Zhou, P.; Zhang, Y.; Liu, H. Multi-objective optimization design and test of compound diatomite and basalt fiber asphalt mixture. Materials 2019, 12, 1461. [CrossRef]

20. Davar, A.; Tanzadeh, J.; Fadaee, O. Experimental evaluation of the basalt fibers and diatomite powder compound on enhanced fatigue life and tensile strength of hot mix asphalt at low temperatures. Constr. Build. Mater. 2017, 153, 238-246. [CrossRef]

21. Veropalumbo, R.; Russo, F.; Viscione, N.; Biancardo, S.A.; Oreto, C. Investigating the rheological properties of hot bituminous mastics made up using plastic waste materials as filler. Constr. Build. Mater. 2020, 121394. [CrossRef]

22. Veropalumbo, R.; Russo, F.; Viscione, N.; Biancardo, S.A. Rheological Properties Comparing Hot and Cold Bituminous Mastics Containing Jet Grouting Waste. Adv. Mater. Sci. Eng. 2020, 1-16. [CrossRef]

23. JTG E20-2011. Standard Test Methods of Bitumen and Bituminous Mixtures for Highway Engineering; China Communications Press: Beijing, China, 2011.

24. JTG F40-2004. Technical Specifications for Constriction of Highway Asphalt Pavements; China Communications Press: Beijing, China, 2005.

25. Xiong, R.; Fang, J.; Xu, A.; Guan, B.; Liu, Z. Laboratory investigation on the brucite fiber reinforced asphalt binder and asphalt concrete. Constr. Build. Mater. 2015, 83, 44-52. [CrossRef]

26. Cheng, Y.; Li, H.; Li, L.; Zhang, Y.; Wang, H.; Bai, Y. Viscoelastic Properties of Asphalt Mixtures with Different Modifiers at Different Temperatures Based on Static Creep Tests. Appl. Sci. 2019, 9, 4246. [CrossRef]

27. Li, P.L.; Jiang, X.M.; Guo, K.; Xue, Y.; Dong, H. Analysis of viscoelastic response and creep deformation mechanism of asphalt mixture. Constr. Build. Mater. 2018, 171, 22-32. [CrossRef]

28. Ho, C.H.; Martin Linares, C.P. Representation Functions to Predict Relaxation Modulus of Asphalt Mixtures Subject to the Action of Freeze-Thaw Cycles. J. Transp. Eng. B Pave 2018, 144, 04018013. [CrossRef]

29. Hajikarimi, P.; Nejad, F.M.; Aghdam, M.M. Implementing General Power Law to Interconvert Linear Viscoelastic Functions of Modified Asphalt Binders. J. Transp. Eng. B Pave 2018, 144. [CrossRef]

30. Zhou, A.; Xie, F.; Zhang, D.; Ji, B.; Chen, L. Viscoelastic parameters determination method of pouring type asphalt mixture based on modified Burgers model. J. For. Eng. 2017, 2, 143-149. (In Chinese)

31. Park, S.W.; Schapery, R. Methods of interconversion between linear viscoelastic material functions. Part I-A numerical method based on Prony series. Int. J. Solids. Struct. 1998, 36, 1653-1675. [CrossRef]

32. Mainardi, F.; Spada, G. Creep, relaxation and viscosity properties for basic fractional models in rheology. Eur. Phys. J. Spec. Top. 2011, 193, 133-160. [CrossRef]

33. Zhang, X.; Gu, X.; Lv, J.; Zhu, Z.; Ni, F. Mechanism and behavior of fiber-reinforced asphalt mastic at high temperature. Int. J. Pavement Eng. 2018, 19, 407-415. [CrossRef]

34. Sun, Y.; Gu, B.; Gao, L.; Li, L.; Guo, R.; Yue, Q.; Wang, J. Viscoelastic Mechanical Responses of HMAP under Moving Load. Materials 2018, 11, 2490. [CrossRef] [PubMed] 
35. Lu, S.; Yin, D.; Meng, R. Stress Relaxation Behavior of Glassy PETG: Experiment and Fractional Model. Polym. Mater. Sci. Eng. 2020, 36, 91-96. (In Chinese)

36. Yu, H.; Shi, G.; Liu, H.; Deng, X.; Cui, X.; Pan, G.; Xi, W. A Nonlinear Viscoelastic Stress Relaxation Model of Rock Based on Fractional Calculus. J. Basic Sci. Eng. 2019, 27, 194-204. (In Chinese)

Publisher's Note: MDPI stays neutral with regard to jurisdictional claims in published maps and institutional affiliations.

(C) 2020 by the authors. Licensee MDPI, Basel, Switzerland. This article is an open access article distributed under the terms and conditions of the Creative Commons Attribution (CC BY) license (http://creativecommons.org/licenses/by/4.0/). 